Guilherme Ribeiro Câmara²

Ada Ávila Assunção ${ }^{3}$

Francisco de Paula Antunes Lima ${ }^{4}$

\title{
Os limites da abordagem clássica dos acidentes de trabalho: o caso do setor extrativista vegetal em Mi- nas Gerais ${ }^{1}$
}

\author{
The limitations of the traditional approach to work accidents: the \\ case of timber exploitation in Minas Gerais, Brazil
}

\begin{abstract}
Resumo
Este estudo, baseado na literatura e no estudo de caso que será apresentado, discute as análises clássicas dos acidentes de trabalho, tendo como foco o setor extrativista vegetal, o qual vem registrando elevadas taxas de mortalidade de trabalhadores em todo o mundo. O estudo articulou duas técnicas: pesquisa documental e observações de campo. Os documentos analisados estavam disponíveis em Comissão Parlamentar de Inquérito. Foram observados os trabalhadores organizados em equipes para cortar as árvores de uma empresa do setor foco. Estudou-se o processo de trabalho por meio de técnicas de observação direta dos trabalhadores. Viu-se predominar nos relatórios técnicos consultados a ideologia do ato inseguro como causa dos acidentes analisados. No entanto, as observações do trabalho evidenciaram determinantes externos dos riscos ocupacionais. Foi possível, ao final, identificar modos operatórios de proteção contra os riscos implementados pelos próprios operadores. Os resultados indicam alguns limites das análises clássicas que não consideram o desenvolvimento da tarefa nas zonas de risco, sendo fonte de idéias preconceituosas sobre o comportamento inseguro dos operadores.
\end{abstract}

Palavras-chaves: acidentes de trabalho, ato inseguro, extrativismo vegetal, saúde do trabalhador.

\begin{abstract}
Based on publications and on a study of a case, the present article discusses traditional analyses of work accidents, focusing on timber exploitation industry, an activity that has been registering increasing mortality rates all over the world. Two techniques were employed: document research and field observation. The documents analyzed were available from the Parliamentary Investigation Commission. The workers observed for this study were divided into teams to cut down trees for a timber company. Their work method was studied by means of direct observation. In the technical reports consulted for the research, causality analyses were led primarily by the unsafe act ideology. However, field observations evidenced external determinants of occupational risks. Final analyses were able to identify methods of protecting against risks implemented by the workers themselves. Results indicate some limitations to traditional analyses that do not take into consideration the performance of tasks within risk zones, leading to biased ideas regarding workers' unsafe behavior.
\end{abstract}

Keywords: occupational accidents, unsafe act, timber exploitation, worker's health. 


\section{Introdução}

A indústria florestal apresenta as maiores taxas de mortalidade associada ao trabalho no mundo, as quais diminuíram em um ritmo menos acelerado do que as doenças registradas no setor (POSCHEN, 1993; CÂMARA, 2004).

A literatura consultada assinala que fatores aleatórios do ambiente na indústria extrativista podem determinar riscos para acidentes, pois se constituem situações nas quais, de maneira dinâmica, a interação de diversos fatores pode transformar situações controladas em não controladas.

O número de trabalhadores expostos e o volume de produção são fatores preditivos positivos para a ocorrência de acidentes nas atividades de corte com uso de motosserra. Entretanto, ainda restam dúvidas quanto às reais causas de acidentes que acontecem na atividade cotidiana dos trabalhadores. Apesar dos achados epidemiológicos, a atividade real, geralmente pouco estudada, deixa obscuros os efeitos da interação dos mecanismos causais dos acidentes do trabalho (LAFLAMME, 1998).

As atividades da colheita de árvore são realizadas, predominantemente, a céu aberto, submetendo os trabalhadores a todas as condições climáticas. Fatores ambientais como a temperatura média na região, as condições geográficas (terreno, relevo e vegetação) e o vento são os elementos que representam os fatores de risco para os acidentes do trabalho no setor florestal conforme descrição da literatura citada a seguir.

As temperaturas no inverno, em estudo realizado na Finlândia, foram identificadas como o principal fator de risco nas atividades de manutenção. A umidade é um fator que aumenta o risco para os trabalhadores florestais, pois, ao tornar escorregadio o solo, cria condições de deslizamento (SLAPPENDEL et al., 1993). Ambientes com baixa luminosidade podem comprometer a segurança, especialmente em atividades de manutenção (VAYRYNEN, 1982).

As diferenças do terreno e o tamanho das árvores podem explicar as diferenças da taxa de mortalidade entre trabalhadores florestais do Estado de Washington quando comparados aos trabalhadores de Ontário (SLAPPENDEL et al., 1993). Em terrenos mais irregulares e com vegetação mais densa, os trabalhadores perdem o equilíbrio e podem cair sobre a motosserra (SLAPPENDEL et al., 1993). Kirk e Parker (1994) citam estudo realizado na Nova Zelândia que identificou, no período de seis anos (1985-1991), a ocorrência de acidentes com perda de tempo (17,5\% dos casos), nos quais os mecanismos descritos foram: tropeção, escorregão e queda associados à umidade já citada, mas, também, às condições do terreno.

Além dos fatores ambientais, determinadas atividades na colheita de madeira são realizadas sem as devidas técnicas e isso favorece a ocorrência de acidentes. A implementação de técnicas inadequadas se deve ao fato de o trabalhador não ter um treinamento para o corte de árvores. Os operadores nem sempre possuem as habilidades necessárias para definir o tipo de motosserra a ser usada, para usar motosserras pesadas ou dominar a situação quando houver "efeito dominó" (KAWACHI apud SLAPPENDEL et al., 1993; CROWE apud SLAPPENDEL et al., 1993).

No entanto, os problemas de segurança não podem ser atribuídos exclusivamente ao tipo de formação do trabalhador. Basta lembrar que os manuais de manutenção nem sempre são acessíveis e os padrões internacionais para o projeto dos equipamentos, às vezes, mostram-se incoerentes. Mais de 40 tipos de configurações para uso de equipamentos na indústria florestal da Alemanha são apresentados na literatura (DYKSTRA \& POSCHEN, 1993). As máquinas adquiridas podem não estar adequadas às características antropométricas dos usuários e aos diferentes terrenos onde serão implantadas. Vale lembrar que os projetos das máquinas são destinados a locais específicos e as máquinas acabam sendo utilizadas em locais diferentes daqueles para os quais foram projetadas. Muitas vezes, a concepção das máquinas resulta da incorporação de diferentes componentes que são aproveitados de outros projetos industriais. As condições ambientais (terreno e tipo de floresta) deveriam ser, mas não são, parâmetros para os projetos das máquinas. Além disso, a manutenção preventiva das máquinas não é a regra, pois existem dificuldades de seguimento de rotinas de manutenção, faltam ferramentas adequadas, as oficinas de reparo são impróprias e não especializadas, além do limite de investimento financeiro (LAFLAMME, 1998). 
A engenharia de segurança é essencialmente fundada em normas e prescrições de atos seguros. Essa abordagem clássica dos acidentes dificulta e não aprofunda as análises habitualmente realizadas que consideram o acidente como o resultado de um ato inseguro, substituem a causa pela culpa ou pela responsabilidade penal e o inquérito policial, conseqüentemente, substitui a análise das circunstâncias e do processo de produção.

Llory (1999) aponta quatro grandes problemas derivados das abordagens clássicas de acidentes. São eles: 1) a posição metodológica e teórica onisciente daqueles que estão realizando uma avaliação; 2) as explicações "psicologizantes”; 3) as assimilações, agregações e generalizações; e 4) o modo de apresentação dos atores envolvidos com o acidente.

A primeira crítica é sobre a posição dos avaliadores, que se colocam no lugar das vítimas de acidentes e são munidos, em tese, de uma bagagem de conhecimentos práticos que elas não tinham. Essa posição perturba a compreensão e a descrição mais completa e detalhada das circunstâncias, dos antecedentes, dos papéis, das funções, dos deslocamentos e das atividades dos atores etc. Assim posicionados, os analistas dos acidentes não compreendem o funcionamento da organização humana em situação de trabalho (ALMEIDA, 2003; DINIZ, 2003).

A abordagem psicologizante busca explicações já prontas, em termos gerais, com referencial a uma atitude psicológica de um determinado "tipo", um comportamento humano "habitual", "natural", até mesmo "universal". Nesse referencial, cabem explicações como a presença de meca-

\section{Materiais e Métodos}

\section{Delineamento do estudo}

O estudo articulou duas técnicas: pesquisa documental e observações de campo. Os documentos analisados estavam disponíveis na CPI. Foram observados os trabalhadores organizados em equipes para cortar as árvores de uma empresa do setor de extrativismo vegetal. Estudou-se o processo de trabalho por meio de técnicas de observação direta dos trabalhadores utilizandose dos procedimentos da escola francesa de ergonomia (GUÉRIN, 2001). nismos psicológicos do tipo: o trabalhador "aplicou a lei do menor esforço", adotou uma conduta individualista, é teimoso e preguiçoso etc.

O limite das abordagens clássicas é classificar os acidentes em geral e identificar como semelhantes as situações que lhes deram origem, mas que, na verdade, são casos particulares e complexos. Generalizando, fica difícil esclarecer os fatores humanos e provocam-se reducionismos que levam a desfalcar, a lascar, a simplificar a humanidade dos indivíduos nos dizeres de Llory (1999).

O autor chama atenção para a forma abstrata da descrição do acidente e dos fatos a ele relacionados. A realidade fica mascarada por ambigüidades, obscuridades, conjecturas e dúvidas. Ora, o evento fatal não pode ser considerado simples, mas sim resultado de causalidades complexas e ramificadas. Vale dizer que os próprios atores do acidente podem esconder explicações ou trazer incompreensões, mal-entendidos ou inibições quando o evento é analisado de forma abstrata.

No lugar de análises superficiais que procuram culpados, o reconhecimento dos determinantes de acidentes pode ter como base uma concepção global que incorpore as relações dinâmicas entre fatores e não mais somente um determinismo causal mecânico (NEBOIT, 1999).

Este estudo de caso busca trazer elementos para elucidar os fatores envolvidos na origem de acidentes fatais ocorridos nas empresas de extrativismo vegetal e registrados na Comissão Parlamentar de Inquérito (CPI) instalada na Assembléia Legislativa de Minas Gerais (ALMG).

\section{Análise documental}

Analisaram-se os documentos disponíveis no arquivo público da ALMG e resultantes da CPI. Foi analisado o conteúdo dos depoimentos registrados e colhidos nas audiências, tendo como foco os casos de acidentes do trabalho fatais no setor.

Os documentos citados representam uma coleção de textos de diferentes estruturas que registram os depoimentos de testemunhas e anexam documentos juntados pelos entrevistados e encaminhados 
por instituições públicas durante os trabalhos da CPI.

Além dos documentos arquivados na ALMG, foram solicitados à Delegacia Regional do Trabalho de Minas Gerais (DRT) os registros de acidentes fatais ocorridos no setor de extrativismo vegetal, sem critério de seleção por empresa, região ou data da ocorrência. Procedeu-se à análise dos temas presentes nos documentos fornecidos e do conteúdo relativo à causa atribuída ao acidente em tela presente no Relatório da Comissão Interna de Prevenção de Acidentes e no relatório preparado pelo auditor fiscal que investigou o caso. Selecionaram-se, pelo critério de qualidade de preenchimento do relatório, quatro casos para apresentação neste artigo.

\section{Análise do processo de trabalho}

Entre as empresas convocadas pela CPI que investigava, por denúncia sindical, os acidentes fatais ocorridos em 2001, uma delas aceitou o estudo em seu ambiente de trabalho. Buscou-se conhecer as principais características da empresa e dos seus métodos de gestão. As informações sobre a empresa foram obtidas por meio de entrevistas com os supervisores de campo, além de consulta a documentos disponibilizados em seu sítio da Internet. Sobre o processo de trabalho, realizou-se observação direta dos trabalhadores em campo na realização das suas tarefas.

\section{Observações das tarefas}

Na empresa estudada, há duas turmas de corte, sendo ambas compostas por 20 equipes, constituídas, cada uma, por dois trabalhadores. Para cada sessão de observação do trabalho, selecionou-se aleatoriamente uma equipe. Ao todo, foram observadas dez equipes.

As observações abertas totalizaram 71 horas e 30 minutos de observação. O pesquisador deslocou-se seis vezes para o campo situado a 180 quilômetros da sede do estudo.

O pesquisador pôde acompanhar a realização de todas as tarefas das equipes de corte durante a permanência em campo. Esse período compreendeu o início de uma jornada de trabalho, desde a saída do acampamento central da empresa, até a chegada nos respectivos locais de corte de árvores.

Durante as observações, registraram-se as comunicações intra e interequipes e os modos operatórios implementados. Foram registradas em fotografias as operações e as atividades da equipe de corte. Utilizou-se de registros em vídeo para analisar alguns procedimentos realizados pelos trabalhadores. Posteriormente, os resultados das observações foram apresentados aos trabalhadores.

\section{Entrevistas}

Foram entrevistados os dirigentes sindicais e os supervisores de campo. Os organizadores da produção foram entrevistados individualmente, visando a conhecer o processo de trabalho.

Foram realizadas três reuniões em campo com os trabalhadores, sendo a primeira com 15 trabalhadores, a segunda com cinco operadores de motosserra e a última com cinco ajudantes florestais. Nessas reuniões, entrevistaram-se os trabalhadores. Procedeu-se à autoconfrontação dos dados obtidos visando a aprofundar pontos específicos e permitir a palavra livre do trabalhador a fim de captar o sentido atribuído por eles mesmos às suas tarefas (ASSUNÇÃO \& LIMA, 2003). Para isso, apresentaram-se os arquivos digitais, expondo o resultado das gravações de vídeo das equipes em atividade. As entrevistas foram gravadas para registro com posterior desgravação.

\section{Resultados da análise dos relatórios de investigação dos acidentes}

Os resultados da análise do registro dos casos de quatro vítimas de acidentes fatais no setor de exploração vegetal da madeira em tora relacionados com a queda de árvores serão apresentados a seguir.

$O$ acidente de trabalho fatal do ajudante florestal A.R.C., 49 anos, aconteceu quando ele estava próximo ao operador de motosserra. Após o início do corte, ao cair, a árvore toca em outra árvore, provocando sua fratura, cujo pedaço vai em direção ao operador, atingindo a sua cabeça. A descrição do acidente encontrada nos documentos oficiais é sumária. Menciona a insegurança do ato da vítima que se localizava tão próximo à zona de risco. Explicita que o ajudante foi mobilizado para ajudar na derrubada da árvore sem explorar as razões da 
proximidade entre os dois trabalhadores da equipe de corte.

Como o trabalhador florestal poderia estar fora da área dita de risco e executar a sua tarefa, que, exatamente, só pode ser realizada na área de risco? Se a presença do trabalhador na área de risco pode levar aos acidentes, então, como garantir a realização do trabalho?

No caso do ajudante S.G.C., 49 anos, registra-se o depoimento sumário do operador de motosserra sem investigar as suas razões para realizar o corte de árvores estando o seu ajudante no terreno, mas fora da sua zona de visão. Encontra-se nos autos:

Informou-nos que havia derrubado e traçado todas as árvores que estavam paralelas à beira da estrada, e logo em seguida, saltou 05 (cinco) árvores e seguiu derrubando duas linhas de árvores em sentido vertical à estrada, após terminada a derrubada, desceu traçando, e, no momento, o ajudante estava observando o traçamento e, ao começar a derrubada do restante das árvores que estavam de pé, o operador disse, nos seus termos: "avisei ao ajudante que iria começar a derrubar, entalhei e direcionei a árvore sentido estrada, ao efetuar a derrubada vi que o ajudante, estava caído".

No caso do acidente com J.R.A., 33 anos, associa-se o sinistro à distração do ajudante florestal que não estaria observando a queda da árvore:

O vento mudou a direção da árvore cortada, o operador gritou alertando o ajudante, este último estava distraído e tentou esconder atrás de outra árvore, mas não deu tempo, a árvore atingiu sua cabeça.

Entretanto, a análise não focaliza as operações do ajudante (suposto distraído) no momento, nem quais seriam os fatores que poderiam comprometer a queda da árvore, além do vento, tampouco se interessa pela maneira de a equipe lidar com os fatores ambientais.

O acidente do trabalho fatal com o operador de motosserra E.M.M., 34 anos, é outro exemplo de uma situação em que uma árvore cai em direção contrária à previsão do corte, atingindo diretamente o operador de motosserra. O relato colhido pelos auditores é claro ao expor que a árvore cortada não cai de imediato, permanecendo em sua posição até que termina por cair fora do tempo e do espaço previstos, acertando o operador de motosserra. E a análise dos autos pára por aí, contentando-se com uma fatalidade da natureza.

Note-se que os dados coletados e descritos acima são frutos de uma análise do acidente realizada por pessoas que não estavam presentes no local e no momento do acidente. Os relatórios estudados não citam as normas de segurança ou a variabilidade da produção que determinariam o surgimento de fatores aleatórios e fora do domínio dos operadores. A complexidade da interação entre os fatores envolvidos na derrubada de uma árvore e sua relação com outras árvores não foi analisada. As questões elaboradas ficam sem os devidos esclarecimentos.

\section{Resultados do estudo do processo de trabalho em uma empresa extrativista}

\section{O setor estudado}

O processo produtivo de colheita de madeira é dividido em diversas fases, sendo elas: plantio, roçamento, derrubada, traçamento, empilhamento, baldeio, carregamento e transporte. O roçamento é a fase de preparação das áreas que receberão em seguida as equipes de corte. São retirados os feixes de galhos espalhados no terreno e ocorre a preparação da zona em torno da árvore que será cortada. As irregularidades e os eventuais buracos no terreno são reparados visando a facilitar o trabalho do corte e melhorar a segurança na área.

Após a derrubada, ocorrerá o corte do tronco da árvore caída em toretes, deno- minado traçamento, e, depois, o empilhamento, iniciado quando outras equipes especializadas fazem pilhas dos toretes da madeira. As pilhas serão organizadas no terreno ou nas margens das estradas de acesso aos locais de corte.

Finalizado o empilhamento, inicia-se o baldeio, por meio de veículo motor, das pilhas até a margem da estrada para facilitar o transporte pelos caminhões. A fase de carregamento consiste na colocação das pilhas de toretes em caminhões e a fase de transporte inclui o deslocamento até o pátio das plantas industriais que irão beneficiar a madeira. Essa fase acontece após o desgalhamento, cuja finalidade é retirar galhos e folhas do tronco principal. 


\section{Os conhecimentos e as habilidades mobi- lizadas pelos trabalhadores}

As verbalizações e os comportamentos observados em campo permitem afirmar que os trabalhadores, na elaboração e na implementação dos seus modos operatórios, levam em conta os constrangimentos de natureza ambiental, como a potencialidade do vento e as irregularidades do terreno. O Quadro 1 permite uma síntese das exigências da produção, da ação desencadeada ou do modo operatório e da competência necessária para a realização da tarefa. Um indicador relevante para a organização real do trabalho é a condição da árvore de corte: contato entre as copas, o estado do tronco da árvore, a provável direção de queda.

Identificaram-se pelos menos três estratégias desencadeadas pelos trabalhadores para evitar acidentes: realizar o corte a partir de seqüência que evite aproximação entre as equipes, deixar algumas árvores como estacas para evitar que a árvore derrubada deslize velozmente pelo terreno após o corte ("chiar" segundo os operadores) e mobilizar, com uso de uma vara improvisada, a árvore "engaiolada”, ou seja, aquela árvore que, após o corte, ficou presa entre as copas das outras.

Os trabalhadores florestais elaboram uma representação específica dos riscos presentes em sua atividade. Um operador de motosserra expressa sua maneira de avaliar precocemente as características do terreno e planejar sua ação integrando os indícios de riscos:

você tem que olhar a posição melhor que as árvores vão cair. Por exemplo, você pega uma grota muito ruim, uma área muito acidentada por exemplo você tem que olhar primeiro ali. Eu vou jogar as árvores em qual posição que ela vai parar com apoio melhor para serrar, mais fácil para cortar.

O operador de motosserra conta com o vento para fazer a derrubada da árvore, ou seja, mesmo que o fator vento cause dificuldades e constrangimentos para a derrubada da árvore no sentido desejado pelo operador, ele pode também ser utilizado para direcionar a árvore. Ele corta a árvore no momento exato que o vento empurra a mesma na direção desejada. Nos seus dizeres:

ver a posição que o vento está ajudando... Você espera o vento, um pouco, às vezes, o vento ajuda. Naquele momento não está ventando, daí uns dois ou três minutos, o vento pega ela e ajuda.

é igual o lugar que nós estamos lá, lugar que nós estamos lá não vale a pena empurrar, porque o serrador está trabalhando a favor do vento. Se estiver caindo bem, você não fica tão naquela situação.

Modos operatórios levam em conta os riscos de acidentes no trabalho

Os trabalhadores usam as expressões: “pega boa” ou "pega ruim”. A “pega” é uma divisão da área, delimitada pela empresa e que será trabalhada pelo conjunto das equipes. Em cada "pega” ficarão dois trabalhadores. As "pegas” são mensuradas pelos organizadores da produção que se utilizam de medidas geométricas para estimar a produtividade.

As características das "pegas" são fortes determinantes da carga de trabalho. A empresa sorteia a "pega" a ser destinada a cada equipe, desvencilhando-se de acusa-

Quadro 1 Descritivo de exigências da produção, ações desencadeadas pelos trabalhadores e competências utilizadas

\begin{tabular}{|l|l|l|}
\hline \multicolumn{1}{|c|}{ Exigência da produção } & \multicolumn{1}{c|}{$\begin{array}{c}\text { Ação desencadeada } \\
\text { (modo operatório) }\end{array}$} & Competências necessárias \\
\hline $\begin{array}{l}\text { não trabalhar próximo às outras } \\
\text { equipes de corte. }\end{array}$ & $\begin{array}{l}\text { realizar o corte numa sequiência contrária à } \\
\text { aproximação entre as equipes. }\end{array}$ & $\begin{array}{l}\text { identificar a tendência de queda das } \\
\text { árvores. }\end{array}$ \\
\hline $\begin{array}{l}\text { preservar a árvore derrubada, } \\
\text { garantir a organização, no terreno, } \\
\text { das árvores derrubadas e preservar } \\
\text { condições de segurança do terreno. }\end{array}$ & $\begin{array}{l}\text { deixar algumas árvores como estacas } \\
\text { para evitar árvore que "chia”. }\end{array}$ & $\begin{array}{l}\text { ter uma representação do pro- } \\
\text { cedimento de traçamento e os } \\
\text { constrangimentos para realizá-lo. }\end{array}$ \\
\hline $\begin{array}{l}\text { determinar com precisão a posição } \\
\text { da árvore no terreno a partir da } \\
\text { derrubada. }\end{array}$ & $\begin{array}{l}\text { mobilização do ajudante florestal com } \\
\text { uso de vara. }\end{array}$ & $\begin{array}{l}\text { identificar dinamicamente durante } \\
\text { a atividade momentos de cons- } \\
\text { trangimento para derrubada. }\end{array}$ \\
\hline
\end{tabular}


ções de favorecimento de uma equipe em detrimento de outra.

Ora, o sorteio de "pegas" tem o potencial de gerar situações acidentogênicas, pois as equipes sem experiência para lidar com as situações de variabilidade ficariam expostas a situações de trabalho com maior exposição a fatores de risco ou vice-versa. Fica claro: os organizadores da produção reconhecem o risco, entretanto, não elaboram medidas de proteção ou de controle, deixando ao acaso a solução do problema.

Considerando os parâmetros citados é que os trabalhadores batizam as "pegas" em boa e em ruim: "a gente até brinca, tem o costume de brincar, é fulano você foi premiado. Todo mundo fica de olho em pega boa", sendo aquela mais limpa, com menos irregularidades no relevo, cujas árvores não têm as suas copas entrelaçadas. Para a "pega” ruim, o contrário é verdadeiro, um operador de motosserra expressa o seu temor em ser escalado para a dita zona: "já fica de botuca, vamos ver quem vai cair ali”.

Existem diversos fatores relacionados com a atividade que determinam uma maior ou menor proximidade do ajudante florestal ao operador de motosserra. A equipe de corte identifica as áreas seguras para sua permanência durante o trabalho. No prescrito, cabe ao operador de motosserra e ao ajudante florestal identificarem suas rotas de fuga após o início do corte da árvore no caso de ter identificado os elementos de variabilidade. Note-se que a área de risco pode ultrapassar a zona prevista pelo método formal de corte da árvore, que supõe o controle total da direção da queda.

A área de risco prevista seria aquela correspondente à direção da queda da árvore. O real subverte a expectativa, pois elementos aleatórios, como a extensão das copas das árvores vizinhas àquela que está sendo derrubada, determinam a direção efetiva da queda da árvore no terreno. $\mathrm{Na}$ realidade do trabalho, a área de risco é toda a circunferência, tendo como diâmetro o tamanho da árvore cortada e as interações, em tempo real, com as demais.

O operador de motosserra deixa algumas árvores no terreno parcialmente cortadas (altura superior à cepa de corte) para fazer barreira para as árvores que, uma vez derrubadas, rolam velozmente pelo terreno, "chiam", nos dizeres dos trabalhadores. A estratégia evita que os troncos sejam danificados após a queda. Mantém-se assim uma organização das árvores derrubadas no terreno e implementa-se uma medida de segurança contra deslizamentos e choques contra os ajudantes florestais ou trabalhadores de equipes mais próximas ao operador de motosserra.

Como os trabalhadores devem atuar em relevos inóspitos devido à irregularidade, proximidade com estradas, áreas de grotas ou áreas de reservas, eles ficam vigilantes e passam a planejar as suas ações incluindo a mobilização de estratégias para realizar o corte da árvore com segurança quando podem. Um operador de motosserra comenta:

ter dificuldade traçar aqui, na hora que você chegar no meio dela, ai, certinho, a árvore vai estar toda alta. Você vai ter que trabalhar com a serra mais alta do que o corpo. Não pode, é perigoso.

Os trabalhadores desenvolveram modos operatórios para atuar nos terrenos considerados mais difíceis, escolhendo um ponto que permita o acesso e a visualização a fim de desenovelar a vegetação, como eles dizem:

primeiro coisa que eu chego, eu olho, os galhos mais ruim, o risco de acidente, penso primeiro o que eu vou fazer, vou cortar aqueles paus primeiro, vou caçar um meio mais fácil para trabalhar. Por mais ruim que a pega seja, ela tem um lado bom para trabalhar. No meio mais fácil, por exemplo. Um meio mais limpo, uma área mais limpa.

Existe um substrato de competências para identificar a "pega" difícil que são as bases para os modos operatórios que o operador irá implementar. Nos seus dizeres:

você tem que procurar facilitar ela, cortar aquelas árvores engaioladas, macacadas primeiro... aqueles riscos de acidentes tem que tirar ele primeiro... não cortar de qualquer maneira, é perigoso.

\section{A interação ajudante-operador-ajudante}

Como medida de segurança na área, o início do trabalho leva em consideração a proximidade de outra equipe, interferindo na escolha do direcionamento das árvores. Uma equipe começa a cortar as árvores que serão derrubadas em um sentido para que, no momento da aproximação de outra equipe, a primeira esteja cortando em posição oposta. O trabalhador relata:

Quando o serrador de lá começar a trabalhar, nós não estamos mais aqui em embaixo, aí as árvores de lá que estão puxando para lá, ai ele vai poder jogar para 
cá tranqüilo, não vamos estar por baixo, não tem perigo, pode trabalhar sossegado. Nossas árvores também que estamos jogando para lá, ele vai trabalhar sossegado que não vai árvore nele.

Os trabalhadores mobilizam a sua competência para evitar aproximação das equipes em campo que poderia expor os colegas às quedas ou a rolamentos de árvores derrubadas pela equipe vizinha. Um operador de motosserra expressa o sentido do seu modo operatório:

se chegar perto, o que tem que fazer. Um tem que atrasar, procurar outra coisa para fazer ou até parar, esperar o outro derrubar.

A referida situação necessita, para o seu controle, de uma grande interação entre ajudante florestal e operador de motosserra.

É imperativo controlar a árvore derrubada. Qualquer dificuldade no seu posicionamento no terreno, após a sua derrubada, pode perturbar toda a atividade dos trabalhadores. Um operador de motosserra explicita: "Uma árvore que cai errado atrapalha o serviço da gente bastante. Atrasa se cai errado".

Note-se que os trabalhadores mobilizam conhecimentos que permitem a elaboração de modos operatórios para controlar as árvores durante a queda, nos seus dizeres:

Se tiver alguém para ajudar perto a gente dá uma força para o ajudante. Tentar empurrar. Se não conseguir. Eu pratico desse jeito. Sempre eu procuro procurar uma árvore próxima para cima e jogar em cima para ver se eu consigo jogar no lugar certo que eu to querendo cair, que eu estou querendo derrubar, mas se de toda maneira não tiver jeito, o lugar que ela virou, você mete uma outra "boca" para cima e joga para cima mesmo.

Existirão equipes com maior ou menor interação. Os trabalhadores considerados mais experientes procuram identificar as situações em que a sua atuação e interação são de vital importância para efetivar uma adequada derrubada da árvore. Um ajudante florestal verbaliza:

Aí vai da equipe né, o ajudante um pouco mais ligado, exemplo, ele tem sincronismo com o serrador que está baleado, ele nem espera o serrador pedir, porque ele ver a precisão e vai empurrar a árvore e vai empurrar já. Você consegue ver que ele está em situação difícil. Se você avalia você usa a vara. Você vê que ele está fazendo força.

Para explicitar as competências requeridas no diagnóstico da dificuldade de derrubada da árvore, o pesquisador perguntou: "Em que hora você vê que a situação é difícil para o operador de motosserra?" A resposta do ajudante florestal foi no seguinte teor:

como exemplo quando ele está numa baixa, aí você repara quando ele joga a serra para outro lado e quando ele puxa, ele tira a mão esquerda da alça da serra e já abre ela em cima da árvore, ele já está fazendo força. O braço já está em cima da árvore fazendo força.

O ajudante é capaz de diagnosticar as perturbações durante a derrubada das árvores e antecipar-se para evitar que as árvores caiam em sentidos não desejados pela equipe. Ele analisa a trajetória possível daquela árvore ao cair, o seu efeito sobre as árvores já derrubadas e como faria para realizar o desgalhamento e o traçamento dela de uma forma eficaz e com segurança.

A mobilização pode acontecer voluntariamente pelo ajudante florestal ou pela convocação do próprio operador de motosserra. Há situações em que os dois membros da equipe de corte dialogam sobre a sua melhor forma de posicionamento no terreno e a direção da árvore que será empurrada. Uma estratégia de derrubar a árvore "enroscada" é provocar um "efeito dominó”, em que uma árvore em pé é jogada em direção à árvore alvo. Para essa operação, o ajudante florestal toca a outra árvore com auxílio de uma vara improvisada para este fim. O operador relata: "a árvore, igual assim, eu estava empurrando, a árvore que vai gastar eu fazer muita força nela”.

Do ponto de vista formal, ajudante florestal é um cargo genérico. Entretanto, ele exerce um papel ativo na equipe de corte e não assume uma postura passiva. Como pôde ser observado várias vezes, ele interage com o operador de motosserra verbal ou fisicamente, empurrando as árvores a serem derrubadas. A interação entre os trabalhadores florestais permite a proximidade dos integrantes da equipe de corte e ambos estarão atuando ao mesmo tempo numa mesma árvore e próximos um do outro. 


\section{Discussão}

A prática hegemônica de análise de acidentes, incluindo a descrição dos acidentes foco deste estudo, encontra respaldo nos resultados de alguns estudos disponíveis na literatura consultada.

Segundo estudos citados por Sant'Anna e Malinovski (2002), cerca de 80\% dos acidentes com operadores de motosserra têm origem em falhas. Trabalhadores que responderam aos questionários preparados para avaliar o peso da falha atribuem $62,5 \%$ das causas de acidentes florestais à falta de responsabilidade do próprio operador. Wasterlund e Kufakwandi (1993) afirmam que a principal causa de acidentes do trabalho é o próprio trabalhador.

Evanson (2001) identifica 22\% dos acidentes devidos a erro humano ou à violação de normas, principalmente na operação de derrubada da árvore. O autor identifica as práticas consideradas "atos inseguros": utilização de veículos em áreas com sinalização para atividades de derrubadas de árvores; técnicas inadequadas para a derrubada, como derrubar próximo a outros trabalhadores; deixar árvores "engaioladas”. Vê-se assim que os resultados das análises dos acidentes em Minas Gerais, que motivaram este estudo, encontram eco em parte dos estudos que prosseguem afirmando as causas sem procurar entender os seus determinantes.

Ostberg (1980), estudando a percepção dos riscos pelos trabalhadores da indústria florestal da Suécia, identificou a seguinte hierarquia de fatores de risco: liberar uma árvore a partir de uma árvore que a suporta ("enroscada"), trabalhar com distância inferior à distância de três árvores entre equipes, liberar uma árvore derrubando outras na direção de outras ("efeito dominó”), interromper a tarefa para realizar uma pausa, deixando uma árvore com corte iniciado sobre outras, não realizar os cortes de abate e direcional, iniciar corte da árvore sem limpar o local no pé da mesma, realizar os cortes para derrubada, mas sem preservar a linha de ruptura, derrubar uma árvore contra um vento forte, empurrar uma árvore após ter feito os cortes para derrubada.

A lista explicita os agentes, mas não busca tecer uma análise mais profunda, que objetivaria entender a rede dinâmica de fatores múltiplos que originam as condições para os acidentes. Menciona-se a debilidade técnica de alguns trabalhadores, no entanto, os resultados obtidos nesta investigação evidenciam a elaboração de estratégias finas por parte dos operadores, os quais estariam buscando interferir sobre mecanismos complexos e não conhecidos da gestão.

Contrariamente às idéias tradicionais sobre causas de acidentes, Poschen (1993) ressalta que, no geral, os trabalhadores têm pouco controle sobre as circunstâncias do trabalho, restando-lhes a possibilidade de domínio apenas sobre a sua atividade. Os resultados apresentados acima esclarecem que os operadores nem sempre podem dominar os fatores climáticos e geográficos, mas nem por isso ficam inertes. Eles elaboram estratégias, desenvolvem habilidades, criam instrumentos, tendo a vara para facilitar a queda da árvore a distância como exemplo.

Sendo estreitas as margens para controlar os fatores aleatórios ligados à geografia, ao clima e à exuberância do objeto do trabalho, árvores que se entrecortam em florestas densas, as características sociais da produção são cruciais como suporte para a implementação de medidas de conforto e de segurança. No entanto, os métodos de gestão não oferecem suporte aos modos operatórios desenvolvidos. Nota-se que o tratamento das situações mais adversas, como árvores "engaioladas", pode ser feito com segurança, caso seja possível a interação dos membros da equipe de corte, pois o trabalhador estará atualizado sobre a posição do outro e, além disso, estarão interagindo para determinar a maneira mais segura de realizar a queda da árvore.

Os resultados apresentados acima indicam que o trabalho realizado durante o corte de madeira tem suas especificidades e é uma atividade complexa. Um exemplo é o "engaiolamento", que dificulta as etapas de desgalhamento, de traçamento e o seu arranjo, pois as toras, ficando dispostas em várias direções, exigirão maior esforço físico dos operadores para deslocá-las. O manuseio da árvore engaiolada pode danificar 
o equipamento, diminuir o rendimento da operação e aumentar o risco de acidentes.

A movimentação da equipe no terreno não é aleatória. Existe cooperação entre as equipes de diferentes áreas de trabalho que sincronizam cada etapa da derruba de árvores, tentando evitar a aproximação das equipes nas fronteiras das suas respectivas áreas, o que poderia expor os colegas às árvores derrubadas pela equipe vizinha.

Além disso, quando existe a possibilidade da aproximação, as equipes mobilizam estratégias específicas para evitar o contato, ou seja, dinamicamente, constroem-se modos operatórios visando a aumentar a segurança das equipes durante o corte das árvores, contrariando a tese do trabalhador despreparado e descuidado presente nos relatórios citados. As estratégias identificadas neste estudo fragilizam a ideologia da falha humana e a idéia de uma adesão ao risco. Paradoxalmente, vê-se o peso da "falha humana" nas análises efetivadas que constam dos relatórios como explicação para as mortes ocorridas.

As regras de segurança são efeito de idiossincrasias. Por exemplo, a distância mínima entre uma equipe de corte e outra, em 1991, era 60 metros, diminuiu para 40 metros em 1997 e, atualmente, é de 30 metros (!). O que teria acontecido para a nítida diminuição da zona de controle e de proteção? A concorrência no mercado e a fratura da organização sindical em tempos de políticas sociais desidratadas explicariam a intensificação da exploração no trabalho?

Ostberg (1980) relata que dois terços dos trabalhadores utilizam, às vezes, métodos proibidos, por exemplo: tratar árvores "enroscadas" cortando a árvore de apoio, jogar uma árvore sobre aquela que está "enroscada" (efeito dominó). A justificativa para o modo operatório de risco é aumentar o número de árvores cortadas, reduzir o gasto de energia e o fato de os operadores não encontrarem, no contexto técnico-organizacional dado, forma mais operacional e segura de fazer a derrubada. Os trabalhadores admitem correr riscos e justificam que quebram regras, pois o tempo disponível para cumprirem suas metas é insuficiente, ou seja, para derrubar uma árvore segundo a prescrição habitual, levam-se cerca de 14 minutos, no entanto, se forem usados métodos proibidos, o tempo seria reduzido para um a quatro minutos (SLAPPENDEL et al., 1993).

À semelhança dos dados colhidos neste estudo, os autores (op. cit., 1993) citam que, em sistemas de pagamento por peças produzidas, o trabalhador utiliza-se de métodos proibidos para economizar sua energia, aumentar a produção e por não haver nenhum outro método mais prático. Ou seja, o trabalhador, em geral, quebraria as normas de segurança, apesar do seu conhecimento sobre os riscos existentes. O sistema de produção não apenas bloqueia as iniciativas de atenuação dos riscos, mas assume uma atitude tolerante com os comportamentos considerados, por eles próprios, inseguros. Vale lembrar que, no caso estudado, eles sorteiam o risco. Ao invés de proceder à elaboração de estratégias de prevenção baseada nos conhecimentos dos trabalhadores, a empresa prefere sortear entre as equipes as áreas perigosas.

No caso citado, identifica-se que a estratégia do trabalhador para realizar a sua atividade é violar a norma de segurança de "não realizar efeito dominó”. Entretanto, não se apresentam os determinantes de tal procedimento, os quais, se reconhecidos, poderiam orientar as medidas de prevenção.

Ostberg (1980) comenta que provavelmente os trabalhadores estejam cientes de inúmeros riscos, mas, apesar disso, permanecem impossibilitados de evitar as lesões quando o risco se materializa, porque a organização do trabalho é tão rígida que a prática de evitar o risco é inviável. Os trabalhadores teriam consciência do risco a que estão expostos e não estariam "alienados" em relação ao mesmo (SLAPPENDEL et al., 1993).

Baseado nos resultados descritos anteriormente, é razoável supor que as análises clássicas deixam escapar que, muitas vezes, a realização da tarefa depende do operador subverter a norma de segurança. Sem analisar o trabalho, haverá pouca chance de o especialista da segurança não incorrer nas idéias pré-concebidas sobre o comportamento de risco do operador. Algumas situações que podem representar riscos para a atividade do operador de motosserra são descritas em manuais de segurança da própria empresa. Trata-se de prescrições de procedimentos seguros para serem executados pelos trabalhadores, entretanto, são contraditórias para a realização dos objetivos da produção. 


\section{Conclusão}

Os resultados obtidos nesta investigação, tendo como foco os acidentes na fase de derrubada de árvores, permitem criticar a superficialidade das abordagens clássicas dos acidentes que não levam em conta

\section{Referências}

ALMEIDA, I. M. Caminhos da análise de acidentes do trabalho. Brasília: Ministério do Trabalho e Emprego/SIT, 2003.

ASSUNÇÃO, A. A.; LIMA, F. P. A. A contribuição da ergonomia para a identificação, redução e eliminação da nocividade do trabalho. In: MENDES, R. Patologia do Trabalho, 2. ed. Rio de Janeiro: Atheneu, 2003. p. 1767-1789.

CÂMARA, G. R. O saber prático dos trabalhadores florestais para evitar acidentes do trabalho durante o corte de madeiras com motosserras. 2004. Dissertação (Mestrado em Saúde Pública) - Faculdade de Medicina, Universidade Federal de Minas Gerais, Belo Horizonte, 2004.

DINIZ, E. P. H. As condições acidentogênicas e as estratégias de regulação dos motociclistas profissionais: entre as exigências de tempo e os constrangimentos do espaço. 2003. Dissertação (Mestrado em Engenharia de Produção) - Escola de Engenharia, Universidade Federal de Minas Gerais, Belo Horizonte, 2003.

DYKSTRA, D.; POSCHEN, P. Wood harvesting. In: STELLMAN, J. M. (Ed.). Encyclopaedia of Occupational Health and Safety. 4. ed., v. 3. Geneva: ILO, 1998. p. 68.1-68.41.

EVANSON, T. et al. Reported near-miss incidents - 1995 to 1999: an exploratory analysis of New Zealand logging industry near-miss-data. Report. v. 2, n. 1, 2001.

GUÉRIN, F. et al. A. Compreender o trabalho para transformá-lo: a prática da ergonomia. São Paulo: Edgard Blücher, 2001.

KIRK, P.; PARKER, R. The effect of spiked boots on logger safety, productivity and a variabilidade das situações de trabalho, tampouco o saber prático dos trabalhadores tanto na elaboração de estratégias para fazer as tarefas do sistema produtivo quanto para evitar os riscos presentes.

workload. Appl. Ergon., v. 25, p. 106-110, 1994.

LAFLAMME, L. Working conditions and safety in forestry work. In: STELLMAN, J. M. (Ed.). Encyclopaedia of Occupational Health and Safety. 4. ed., v. 3. Geneva: ILo, 1998. p. 68.1-68.41.

LLORY, M. Acidentes industriais: o custo do silêncio. Rio de Janeiro: Multimais Editorial, 1999.

NEBOIT, M. Abordagem dos fatores humanos na prevenção de riscos do trabalho. 1999. Disponível em: http:// www.trabalho.gov.br. Acesso em: 15 set. 2003.

OSTBERG, O. Risk perception and work behaviour in forestry: implications for accident prevention policy. Acci. Anal. and Prevent, v. 12, p. 189-200, 1980.

POSCHEN, P. Forestry, a safe and healthy profession? Unasylva, v. 44, n. 1, issue 172, p. 3-12, 1993.

SANT'ANNA, C. M.; MALINOVSKI, J. R. Análise de fatores humanos e condições de trabalho de operadores de motosserra de Minas Gerais. CERNE, Lavras, v. 8, n. 1, p. 115-121, 2002.

SLAPPENDEL, C. et al. Factors affecting work-related injury among forestry workers: a review. J. S. Res., v. 24, n.1 p. 19-32, 1993.

VAYRYNEN, S. Occupational accidents in the maintenance of heavy forest machinery. J. Oсcup. Асc., v. 4, p. 175, 1982.

WASTERLUND, D. S.; KUFAKWANDI, F. Improving working conditions. In: ZAFICCO, Zambia's parastatal forest industry. Unasylva, v. 44, n. 1, issue 172, p.13-18, 1993. 